\title{
Cotidiano familiar: refletindo sobre a saúde mental infantil e a prática de atividades familiares
}

\section{Daily family life: reflecting on child mental health and the practice of family activities}

\author{
Maria Fernanda Barboza Cid
}

http://dx.doi.org/10.11606/issn.2238-6149.v26i3p428-438

Cid MFB. Cotidiano familiar: refletindo sobre a saúde mental infantil e a prática de atividades familiares. Rev Ter Ocup Univ São Paulo. 2015 set.-dez.;26(3):428-38.

RESUMO: Considerando que o cotidiano de crianças em idade escolar é principalmente pautado no contexto familiar, o objetivo deste estudo foi identificar as atividades cotidianas de famílias de crianças em idade escolar e relacioná-las à saúde mental das mesmas. Foram participantes, 321 responsáveis por estudantes do ensino fundamental de escolas públicas de uma cidade do interior do Estado de São Paulo/Brasil. Para a coleta de dados foi utilizado o Questionário de Atividades Cotidianas, desenvolvido pela pesquisadora e a versão brasileira do Questionário de Capacidades e Dificuldades para avaliação da saúde mental das crianças. Os dados foram analisados de forma descritiva e correlacional. Os resultados indicaram que as crianças que pertencem a famílias em que existem regras e responsabilidades apresentaram maiores níveis de comportamento pró-social. Por outro lado, o baixo desempenho escolar e a existência de "brigas na família" estão associados a prejuízos na saúde mental infantil. Discute-se que a existência de regras e responsabilidades que organizam a rotina das crianças, faz parte do conjunto de ações que caracterizam práticas parentais positivas que, por sua vez, se configuram como relevante mecanismo protetivo para a saúde mental e desenvolvimento destas crianças.

DESCRITORES: Atividades cotidianas; Saúde mental; Criança; Fatores de risco; Relações familiares.
Cid MFB. Daily family life: reflecting on child mental health and the practice of family activities. Rev Ter Ocup Univ São Paulo. 2015 Sept.-Dec.;26(3):428-38.

\begin{abstract}
Understanding that the daily life of school-age children is grounded in the context of the family, the purpose of the study was to identify the daily activities of families with children and relate these to their mental health status. The participants were 321 families of children attending primary education in public schools of a city, in the State of São Paulo/ Brazil. Data were collected through the application of Activities of Daily Living Questionnaire, developed by the researcher and the mental health of the children was assessed using the Brazilian version of Strengths and Difficulties Questionnaire. The data were submitted to descriptive and correlational analyses. The results indicated that children whose children belonging to families with rules and responsibilities that all members understood and complied by showed higher levels of prosocial behavior. In contrast, poor school performance and the existence of family conflicts were associated with impairment in children mental health. Thus, the existence of rules and responsibilities for organizes the routine of children, forms part of the set of actions that characterize positive parenting practices and are a relevant protective mechanism for the mental health and development of these children.
\end{abstract}

KEY WORDS: Activities of daily living; Mental health; Child; Risk factors; Family relations.

O trabalho é parte integrante da tese de doutorado, defendida no Programa de Pós-Graduação em Educação Especial da Universidade Federal de São Carlos, Departamento de Terapia Ocupacional.

Endereço para correspondência: Departamento de Terapia Ocupacional da Universidade Federal de São Carlos - Rod. Washington Luís, Km: 235, Monjolinho. São Carlos, SP. E-mail: mariafernandacid@gmail.com 


\section{INTRODUÇÃO}

$\mathrm{E}$ studos têm apontado que as características do contexto familiar têm sido exploradas e identificadas como importantes influências na saúde mental de crianças ${ }^{1,2}$.

No que se refere aos estudos brasileiros que investigaram especificamente associações entre o desenvolvimento de problemáticas de saúde mental infantil e os fatores de risco e proteção envolvidos nesse processo, tem-se o estudo de Ferrioli et al. ${ }^{3}$ que objetivou identificar crianças em risco para problemas emocionais junto aos usuários de um Núcleo de Atenção Primária do Programa de Atenção Primária e Saúde da Família. Participaram, 100 crianças de 6 a 12 anos de idade. As autoras encontraram associações entre a presença de transtornos emocionais nas crianças e a presença de situações adversas nos contextos familiar e escolar e também de dificuldades escolares.

Sá et al. ${ }^{4}$ desenvolveram a fase piloto do Estudo Brasileiro de Violência Doméstica contra a Criança e o Adolescente, vinculado à pesquisa multicêntrica internacional World Studies of Abuse in the Family Environment (WorldSAFE), com o objetivo de identificar fatores associados a problemas de saúde mental em crianças e adolescentes em amostra probabilística de 67 crianças e adolescentes e suas mães residentes em dois conglomerados do município de Embú/SP. Foram encontradas associações entre problemas de saúde mental infantil e as seguintes variáveis: a criança ser do gênero masculino, sofrer punição física grave, ideação suicida da mãe, violência conjugal física contra a mãe e embriaguez do pai/padrasto.

Assim, aponta-se que a família, independente de sua configuração, se caracteriza, dentre outras coisas, por proporcionar relações de afeto e de compromisso entre os membros, relações estas que são dinâmicas e que se modificam ao longo do tempo ${ }^{5}$.

As características das relações estabelecidas no contexto familiar exercem um papel importante no desenvolvimento das crianças e adolescentes e, pensando especificamente na relação entre criança/adolescente e seu responsável, a compreensão de práticas e estilos parentais contribui para o melhor entendimento deste processo.

Observa-se que no dia a dia familiar, os pais utilizam diversas estratégias para orientar as ações dos filhos no cotidiano e promover sua independência e socialização. Tais estratégias e técnicas utilizadas pelos pais na educação dos filhos são denominadas práticas educativas parentais ${ }^{6,7}$.

$\mathrm{O}$ resultado do uso de um conjunto de Práticas Educativas Parentais é denominado Estilo Parental ${ }^{6,8}$, que pode ser entendido como a maneira que os pais lidam com as questões de poder, hierarquia e apoio emocional na relação com os filhos. Cecconello ${ }^{7}$ aponta que o Estilo Parental é o padrão global de características da interação dos pais com os filhos em diversas situações, gerando um clima emocional.

Considerando que as práticas e estilos parentais compreendem os processos de interação entre mães/pais (responsáveis/cuidadores) e crianças, expressas no contexto familiar, a partir da dinâmica cotidiana, neste estudo, buscou-se aprofundar nesse processo, para além das práticas e estilos parentais, com o intuito de melhor compreender a natureza das atividades e relações vivenciadas pelas crianças no interior de suas famílias.

Muniz et al. ${ }^{9}$, focalizando as atividades de rotina desempenhadas pelas crianças em idade pré-escolar no contexto familiar, desenvolveram um estudo quantitativo, envolvendo 8850 crianças norte americanas, com o objetivo de identificar correlações entre a participação das crianças em atividades familiares de rotina e a saúde mental. As atividades consideradas foram: 1. refeições em família; 2. contar histórias, cantar ou ler junto com os pais e 3 . brincar ou jogar junto com os pais. A frequência semanal de realização das atividades também foi avaliada pelo estudo. Os resultados indicaram que as crianças que participavam de atividades de rotina familiares apresentaram melhores níveis de saúde mental e que quanto mais atividades e quanto mais frequentes elas fossem, maiores os níveis de saúde mental ${ }^{9}$.

A partir dos resultados, as autoras apontam a necessidade de ações cada vez mais precoces de promoção do desenvolvimento socioemocional de crianças, que levem em consideração o contexto familiar e a organização das rotinas familiares ${ }^{9}$.

Nessa direção, o estudo tratado aqui procurou investigar a rotina de atividades e relações vivenciadas pelas crianças no cotidiano da família e sob a ótica dos responsáveis pelas crianças.

Aponta-se que o cotidiano, aqui, é compreendido como um constructo que, segundo Heller ${ }^{10}$ se expressa e se desenvolve ao longo da vida, a partir de um processo que se torna mais complexo com a maturidade, em termos das relações pessoais, manipulação dos objetos e das tarefas diárias. A autora aponta, ainda, que a dinâmica de organização do trabalho, do lazer e das relações sociais são partes orgânicas do cotidiano.

Refletindo sobre o processo da vida cotidiana, Galheigo ${ }^{11}$ sinaliza que o cotidiano do homem se dá a partir de suas singularidades (percepções, valores, motivações, sentidos, crenças) e também da coletividade, considerando as atividades com caráter genérico, tais como as de trabalho, artísticas, de cuidado ao outro, de participação social e política. 
Assim, compreendendo que o cotidiano de crianças em idade escolar é pautado principalmente no contexto familiar, e que as dinâmicas de atividades e relações deste contexto são o pano de fundo para o processo de desenvolvimento da criança, apresenta-se, a seguir, os principais elementos do estudo que teve como objetivo identificar as atividades cotidianas de famílias de crianças estudantes do primeiro ao quinto ano de escolas municipais da cidade de São Carlos, interior do Estado de São Paulo e relacioná-las à saúde mental das mesmas.

\section{MÉTODO}

\section{Participantes}

Foram participantes do presente estudo 321 responsáveis por crianças estudantes do primeiro ao quinto ano do ensino fundamental de cinco escolas da Rede Municipal de Ensino da cidade de São Carlos, interior do Estado de São Paulo.

\section{Instrumentos}

\section{Questionário de atividades cotidianas - QAC}

Para a identificação dos dados gerais da família e das atividades cotidianas presentes no dia-adia das crianças, foi construído pelas pesquisadoras um questionário com 42 questões abertas e fechadas.

As atividades cotidianas familiares abordadas foram: vivência de atividades de lazer pela criança e família, vivência de atividades religiosas, sobre a rotinas, regras e responsabilidades que os membros familiares devem cumprir, sobre brigas/discussões no ambiente familiar, atividades desenvolvidas pela criança no período que não está na escola, atividades compartilhadas entre responsável e criança no cotidiano, dentre outras.

Aponta-se que o questionário foi elaborado a partir de apontamentos da literatura referente aos fatores de risco e proteção vinculados ao contexto familiar que possivelmente estão envolvidos na determinação da saúde mental infantil.

\section{(SDQ):}

\section{Questionário de capacidades e dificuldades}

$\mathrm{O} \mathrm{SDQ}^{12}$ foi utilizado para avaliar problemas de saúde mental infantil. É composto por 25 itens, subdivididos em 5 subescalas que avaliam: hiperatividade, sintomas emocionais, problemas de conduta, relações interpessoais e comportamento pró-social. Ressalta-se que esse instrumento investiga sintomas e avalia o impacto dos mesmos na criança/adolescente, em sua vivência familiar e escolar, através de três versões, a saber: para pais, professores e crianças ou adolescentes. No presente estudo foi utilizada a versão para pais, que foi apresentada aos responsáveis pelas crianças.

Esse questionário tem sido traduzido e validado para mais de quarenta países, apresentando tradução, também, para o português ${ }^{13}$.

\section{Procedimentos}

\section{Validação qualitativa do QAC e aplicação - teste}

Para validação, o QAC, foi submetido à apreciação de cinco juízes especialistas da área de saúde mental infantil e estudiosos dos fatores de risco e proteção ao desenvolvimento infantil, que avaliaram a pertinência das questões colocadas em função dos objetivos do estudo e emitiram sugestões que balisaram a reformulação e aplicação do instrumento ${ }^{14}$.

Após a revisão do Questionário de Atividades Cotidianas, conforme sugestões recebidas dos juízes, todos os instrumentos foram submetidos a aplicações-teste junto a responsáveis por crianças estudantes do primeiro ciclo do ensino fundamental da cidade de São Carlos que não fariam parte da amostra do estudo. O objetivo da aplicação teste foi o aperfeiçoamento da forma de aplicação dos instrumentos de medida, a avaliação da clareza dos mesmos pelos participantes, a verificação do tempo necessário com cada participante para a realização da coleta de dados e o treino da equipe de pesquisadores.

\section{Identificação de participantes e coleta de dados}

A composição da amostra de participantes se deu a partir do número de crianças matriculadas nas escolas. Definida a amostra, foi elaborada a carta-convite para os pais dos alunos sorteados contendo informações sobre o estudo e sobre o fato de que um membro da equipe da pesquisa entraria em contato por telefone ou diretamente na residência, para convidá-los pessoalmente para a participação.

Após o envio das cartas, foi iniciado o contato com os responsáveis, por telefone e a partir de visitas domiciliares. Para aqueles que aceitavam participar, um encontro era agendado e os instrumentos de coleta de dados, aplicados, mediante a assinatura do Termo de Consentimento Livre e Esclarecido. 


\section{Análise dos dados}

Os dados referentes ao SDQ foram tratados a partir de suas planilhas de cálculo. Os dados advindos do QAC foram categorizados e tabulados. Análises descritivas e correlacionais foram feitas, sendo que para as análises de correlação, foram utilizados os seguintes testes estatísticos: teste de Correlação de Kendall's; teste de Mann-Whitney e teste de Kruskall-Wallis. Os testes foram considerados com resultado significante quando o valor da estatística que o descreve (p-valor) era menor do que 0,05, admitindo-se como probabilidade de erro o valor de 5\%. Para a realização das análises estatísticas, utilizou-se o Software Statística 7.

\section{RESULTADOS}

Nesta seção serão apresentados os principais resultados obtidos no presente estudo, que estarão organizados da seguinte forma: primeiramente, no item "Resultados descritivos do Questionário de Atividades Cotidianas". Serão apresentados os dados descritivos do QAC e no item "Resultados das análises de correlação

Tabela 1 - Caracterização dos responsáveis pelas crianças

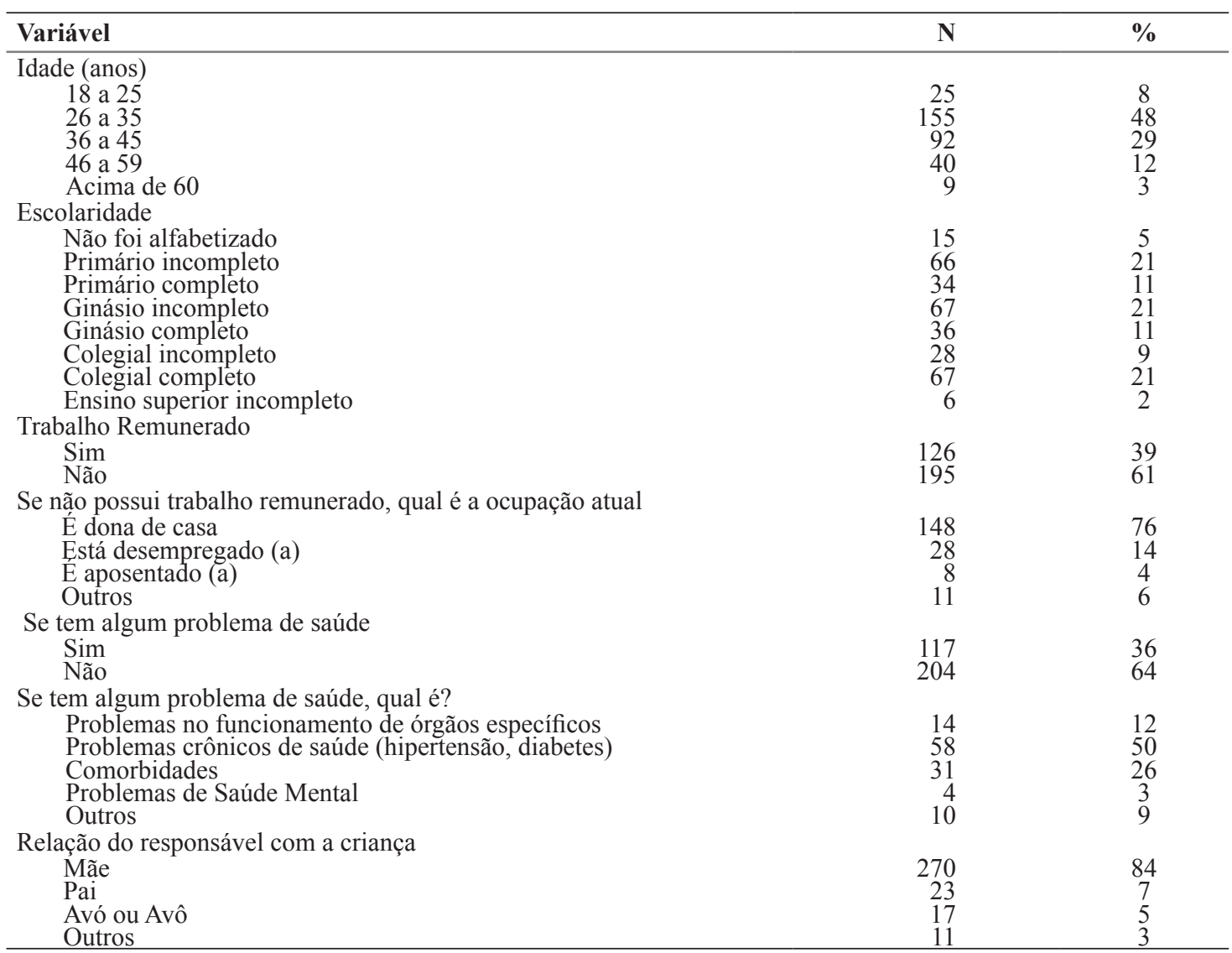

e comparação entre as variáveis: saúde mental infantil e variáveis do cotidiano e contexto familiar ( $Q A C)$ )". Serão apresentadas as relações identificadas entre o QAC e o SDQ.

\section{Resultados descritivos do Questionário de Atividades Cotidianas}

As variáveis do QAC abordaram 4 dimensões:

Dimensão 1: Responsável;

Dimensão 2: Criança;

Dimensão 3: Família;

Dimensão 4: Práticas de cuidado do responsável em relação à criança.

A seguir serão apresentados os dados descritivos do QAC a partir de cada uma das quatro dimensões.

\section{Dimensão 1: Responsável}

Apresentam-se a seguir, na Tabela 1, os dados de caracterização dos responsáveis. 
Observa-se na Tabela 1 que $48 \%$ dos responsáveis possuem idade de 26 a 35 anos; em relação à escolaridade, $5 \%$ dos responsáveis não foram alfabetizados, e $21 \%$ apresentam primário incompleto. Também $21 \%$ dos responsáveis possuem ginásio incompleto e outros $21 \%$ colegial completo.

Sobre a situação de trabalho $61 \%$ dos responsáveis não têm trabalho remunerado, sendo, a maioria, "donas de casa".

Em relação ao estado de saúde do responsável, $34 \%$ declaram que possuem problemas de saúde, sendo que desses, a maioria $50 \%$ relata problemas crônicos, tais como hipertensão e diabetes. Apenas 4 pessoas relatam apresentar problemas relacionados à saúde mental.

No que se refere à relação entre responsável e criança, verifica-se que as mães representam a maioria dos participantes do estudo (84\%).

Os responsáveis foram questionados, também, sobre se há alguém que o auxilia na criação e educação da criança no cotidiano. A partir dos dados observa-se que os cônjuges são os principais atores apontados pelos responsáveis no que se refere ao auxílio à criação das crianças $(57 \%)$. Além deles, os pais e irmãos do responsável também são indicados por 13\% dos participantes. No entanto, $16 \%$ dos responsáveis apontam que ninguém os ajuda na educação das crianças.

A seguir, apresentam-se os resultados relacionados às crianças.

\section{Dimensão 2: Criança}

Na Tabela 2 encontram-se os dados de gênero, idade, escolaridade e desempenho escolar das crianças.

Tabela 2 - Caracterização das crianças envolvidas no estudo

\begin{tabular}{lll}
\hline Variável & N & $\%$ \\
\hline Gênero & 157 & 49 \\
Masculino & 164 & 51 \\
Feminino & 124 & 39 \\
Idade (anos) & 137 & 43 \\
6-8 & 59 & 18 \\
$9-10$ & 62 & 19 \\
acima de 10 & 158 \\
Desempenho escolar das crianças na visão do responsável & 74 \\
Muito bem & 15 & 23 \\
Bem & 12 & 4 \\
Mais ou menos & 5 \\
Mal & 62 \\
Muito mal & 19 \\
Se a criança já repetiu de ano & 259 & 81 \\
Sim & & 55 \\
Não & 177 & 55 \\
Se a criança vivencia uma rotina de atividades programadas no cotidiano & 144 \\
$\quad$ Não & 45 \\
\hline
\end{tabular}

Nota-se um equilíbrio entre os gêneros das crianças participantes. Em relação à idade, a maioria possui 9 ou 10 anos. No que se refere ao desempenho escolar das crianças, na visão dos responsáveis, verifica-se que a maioria aponta que as crianças "vão bem" na escola, sendo que 19\% das crianças já repetiram de ano pelo menos uma vez. Observase, também, um equilíbrio entre o número de crianças que possuem e não possuem atividades de rotina.

Sobre as atividades exercidas pela criança no período que ela não está na escola, os resultados mostraram que:

- 68\% das crianças ficam em casa brincando ou assistindo TV no período que não estão na escola;

- $21 \%$ das crianças variaram entre ficar em casa ou na rua ou em outras atividades, não havendo um padrão nas atividades que elas desenvolvem no período que não estão na escola; 


\section{- $6 \%$ ficam brincando na rua ou na casa de amigos \\ e; \\ - 5\% ficam em instituições que abrigam crianças} no período oposto à escola.

\section{Dimensão 3: Família}

A seguir, na Tabela 3 apresentam-se informações sobre a situação conjugal dos pais, número de irmãos da criança e renda familiar declarada pelos responsáveis.

Tabela 3 - Situação conjugal dos pais, número de irmãos que a criança possui e renda familiar

\begin{tabular}{lcc}
\hline Variável & N & $\%$ \\
Situação conjugal dos pais & 210 & 65 \\
Vivem juntos & 111 & 35 \\
Não vivem juntos & & 10 \\
Quantos irmãos a criança possui & 37 & 60 \\
Nenhum & 190 & 30 \\
Um ou dois & 94 & 5 \\
Três ou mais & & 5 \\
Renda familiar declarada* & 16 & 64 \\
Sem rendimento & 206 & 29 \\
Até 2 salários mínimos & 93 & 5 \\
De 2 a 5 salários mínimos & 5 & 2 \\
De 5 a 10 salários mínimos
\end{tabular}

Legenda: *O salário mínimo em vigor no período de realização da coleta de dados correspondia a $\mathrm{R} \$ 465,00$

Observa-se que a maior parte das crianças foco do presente estudo vivem com ambos os pais, em famílias nucleares. Em relação aos irmãos, verifica-se que cerca de $60 \%$ das crianças possui um ou dois irmãos. No que se refere à renda familiar declarada pelo responsável, a maioria (206 famílias) possui renda de até 2 salários mínimos (até $\mathrm{R} \$ 930,00)$.

Sobre a existência de regras e responsabilidades na família, pôde-se verificar que em $43 \%$ das famílias não existem regras e responsabilidades que todos conhecem e cumprem.

Para os participantes que relataram que em suas famílias existem responsabilidades e regras que todos os membros conhecem e cumprem (57\%), foi solicitado que eles informassem exemplos das atividades cotidianas que representavam as regras e as responsabilidades.

Verificou-se que 111 das 183 famílias adotam regras e responsabilidades que se referem às atividades domésticas (arrumar as camas, lavar a louça, limpar a casa), as demais apontaram a existência de horários fixos de rotina, tais como horário para as refeições e para a lição de casa, por exemplo.

Sobre os dados referentes à questão que abordou as atividades compartilhadas por responsáveis e crianças durante a semana pôde-se observar que 57 dos participantes relataram que não costumam realizar nenhuma atividade junto às crianças no cotidiano. A maioria realiza um ou dois tipos de atividades. Ressalta-se que esta questão era aberta e, as principais atividades relatadas pelos responsáveis foram: realizar refeições junto com as crianças, assistir TV junto, ir à casa de familiares, realizar tarefas domésticas, conversar e brincar.

Com o objetivo de investigar a existência de algum tipo de violência intrafamiliar, algumas questões foram feitas para os participantes, e pôde-se verificar que 31\% dos participantes relatam que existem "brigas" no ambiente familiar, sendo que a maioria dessas "brigas" são relatadas como sendo do tipo "discussões" (90\%). 


\section{Dimensão 4: Práticas de cuidado do responsável em relação à criança}

A seguir apresenta-se o Gráfico 1 com os resultados referentes às práticas de cuidado dos responsáveis com as crianças.

Gráfico 1 - Práticas de cuidado do responsável em relação à criança

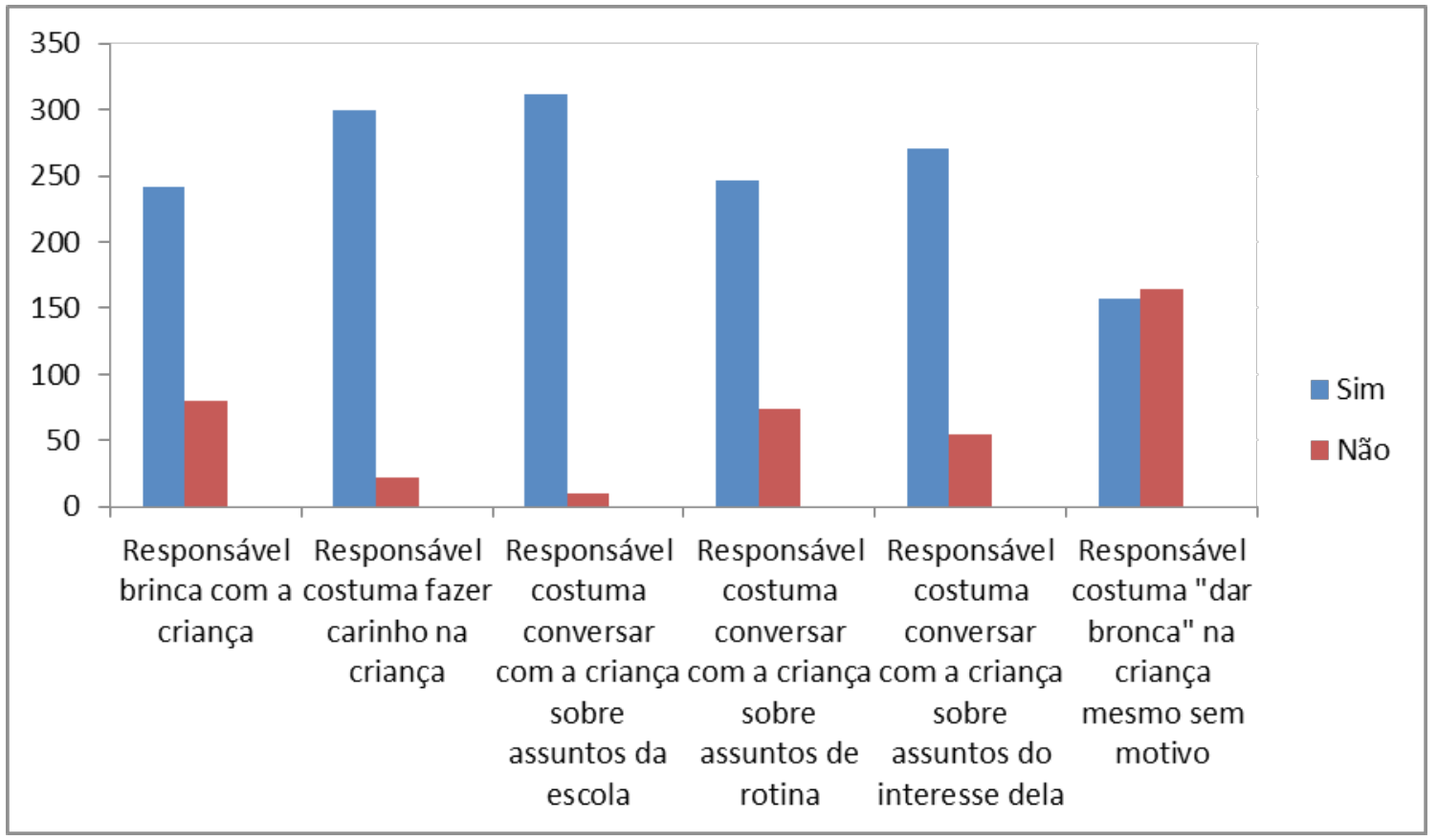

Observa-se que metade dos responsáveis indicam que costumam dar "bronca" na criança mesmo sem a existência de um motivo. A maioria dos responsáveis relata que possui o hábito de fazer carinho nas crianças e de brincar com as mesmas. No que se refere ao diálogo/conversa estabelecida entre responsável e criança, verifica-se que a maioria dos responsáveis relata que conversa, sendo o assunto principal a escola.

\section{Resultados das análises de correlação e comparação entre as variáveis: saúde mental infantil e variáveis do cotidiano e contexto familiar (QAC)}

A partir das análises realizadas, verificou-se que nenhuma relação foi identificada relativa às variáveis da Dimensão 1 do QAC e à saúde mental das crianças. Portanto, no Quadro 1 a seguir apresentam-se os resultados encontrados a partir das análises entre algumas variáveis das Dimensões 2, 3 e 4 e a saúde mental infantil.
As análises referentes ao Contexto Familiar relacionadas à Saúde Mental Infantil que registraram resultados estatisticamente significativos são ilustradas no Quadro 1, a partir da qual é possível verificar que as variáveis que parecem influenciar a saúde mental infantil (expressa pelo Total de Dificuldades) são: Desempenho da criança na escola segundo a visão do responsável, Se a criança já repetiu de ano", Se o responsável "dá muita bronca na criança" e "se há brigas na família".

É possível verificar, também, que a subescala do SDQ que mais obteve relações com as variáveis do contexto familiar foi "Problemas de Conduta", cujos escores se correlacionaram ou apresentaram diferenças entre os grupos em sete das nove variáveis avaliadas.

Em relação às variáveis, observa-se que a que mais se relaciona ao desenvolvimento de problemas de saúde mental nas crianças é "brigas na família", ao passo que as variáveis que se relacionaram com o comportamento pró-social nas crianças foram: "Se na 
família existem regras e responsabilidades" (nas famílias que os responsáveis relataram a existência dessa variável, as crianças apresentaram mais esta habilidade) e "se há brigas na família" (nas famílias que os responsáveis relataram a existência de "brigas", as crianças apresentaram menos esta habilidade).

Quadro 1 - Correlações identificadas entre os escores do SDQ e as variáveis QAC

\begin{tabular}{|c|c|c|c|c|c|c|c|c|}
\hline \multicolumn{9}{|c|}{ Resumo das diferenças e correlações significativas entre os escores do SDQ e as variáveis do QAC } \\
\hline QAC/SDQ & & $\begin{array}{l}\text { Sintomas } \\
\text { Emocionais }\end{array}$ & $\begin{array}{l}\text { Problemas } \\
\text { de } \\
\text { Conduta }\end{array}$ & Hiperatividade & $\begin{array}{l}\text { Problemas de } \\
\text { Relacionamento }\end{array}$ & $\begin{array}{l}\text { Comportamento } \\
\text { Pró-Social }\end{array}$ & $\begin{array}{l}\text { Total de } \\
\text { Dificuldades }\end{array}$ & $\begin{array}{l}\text { Suplemento } \\
\text { de Impacto }\end{array}$ \\
\hline \multirow{3}{*}{ Dimensão 2} & $\begin{array}{l}\text { Desempenho da } \\
\text { criança na escola }\end{array}$ & & & $\mathrm{X}$ & & & $\mathrm{X}$ & $\mathrm{X}$ \\
\hline & & & & & & & & \\
\hline & $\begin{array}{l}\text { Se a criança já } \\
\text { repetiu de ano }\end{array}$ & & $\mathrm{X}$ & $\mathrm{X}$ & & & $\mathrm{X}$ & $\mathrm{X}$ \\
\hline \multirow{3}{*}{ Dimensão 3} & $\begin{array}{l}\text { Se os pais da } \\
\text { criança vivem } \\
\text { juntos }\end{array}$ & & $\mathrm{X}$ & & $\mathrm{X}$ & & & \\
\hline & $\begin{array}{l}\text { Se na familia } \\
\text { existem regras e } \\
\text { responsabilidades }\end{array}$ & & & & & $\mathrm{X}$ & & \\
\hline & $\begin{array}{l}\text { Se há brigas na } \\
\text { família }\end{array}$ & & $\mathrm{X}$ & $\mathrm{X}$ & $\mathrm{X}$ & $\mathrm{X}$ & $\mathrm{X}$ & \\
\hline Dimensão 4 & $\begin{array}{l}\text { Conversa sobre } \\
\text { assuntos do interesse }\end{array}$ & & $\mathrm{X}$ & & & & & \\
\hline
\end{tabular}

\section{DISCUSSÃO E CONSIDERAÇÕES FINAIS}

Os resultados do presente estudo sinalizaram reflexões e discussões referentes ao cotidiano familiar e a saúde mental de crianças em idade escolar.

Sobre as variáveis identificadas pelo Questionário de Atividades Cotidianas e que se relacionaram significativamente à saúde mental das crianças, observouse que o fato de as famílias apresentarem em seu contexto regras e responsabilidades que todos os membros conhecem e precisam cumprir configurou-se como um possível fator de proteção à saúde mental infantil, na medida em que se relacionou com a subescala "Comportamento PróSocial" do SDQ, apresentando diferenças estatisticamente significativas entre os grupos, sinalizando que as crianças que vivem em famílias nas quais essa prática existe, apresentam mais a habilidade de se comportar de forma prósocial do que as crianças que não vivenciam essa realidade. Vale observar que o fato de na família existirem regras e responsabilidades que de certa forma organizam a rotina dos membros familiares, inclusive das crianças, faz parte do conjunto de ações que caracterizam as práticas parentais positivas ${ }^{6,15}$. Gomide ${ }^{6}$ aponta que a existência de regras e limites na família, sugeridas e acompanhadas 
pelos responsáveis, bem como a monitoria das atividades de rotina da criança a partir de um contexto de afeto e respeito favorecem o desenvolvimento de comportamentos prósociais nas crianças, sendo identificada no presente estudo como um potencial fator de proteção à saúde mental infantil.

Para somar a esta reflexão, apresentam-se outros elementos que foram identificados no presente estudo, embora não tenham sido relacionados significativamente com a saúde mental das crianças.

Um deles se refere à criança ter uma rotina de atividades que se repete em seu cotidiano. Observou-se que $55 \%$ das crianças, segundo os responsáveis, possuem esta rotina. Acredita-se que a rotina identificada pelos responsáveis se refere, principalmente, à atividade escolar da criança, na medida em que quando esta não está na escola, em sua maioria (66\%), está em casa com atividades mais livres. A despeito disso, o responsável por estas crianças identificam a existência de uma rotina, diferente dos responsáveis de $45 \%$ das crianças que não a identificam.

Tais achados remetem à reflexão a respeito de como as famílias têm organizado e monitorado o cotidiano das crianças em idade escolar e a partir de quais recursos fazem isso. Ou se não fazem, o porquê. Mais estudos que se dedicassem a investigar a dinâmica cotidiana de famílias com crianças podem contribuir no sentido de melhor compreender como as famílias de diferentes contextos socioeconômico-culturais têm cuidado e organizado a rotina das crianças e qual o impacto de tais práticas no desenvolvimento socioemocional das crianças.

Os achados do presente estudo sinalizam para uma questão importante a ser considerada tanto pelos profissionais de serviços de saúde e educação que atendem crianças com problemas relativos à saúde mental ou não, bem como pelas políticas e intervenções de prevenção e promoção à saúde mental infantil, no sentido de planejar e implementar estratégias que possibilitem às crianças terem rotinas de atividades organizadas e respeitadas nos ambientes em que vivem, em especial, escola e família.

Para além da organização da rotina e do monitoramento das atividades das crianças, aponta-se que a dinâmica das relações de afeto expressas no contexto familiar também pode impactar o desenvolvimento socioemocional das crianças.

Nessa direção, quando os responsáveis foram questionados a respeito das atividades que compartilham com as crianças no cotidiano, observou-se que $67,9 \%$ dos participantes responderam que compartilham uma ou duas atividades com a criança ao longo da semana, sendo as atividades apontadas: as refeições, assistir TV junto, conversar e brincar. Além disso, $75 \%$ relataram que costumam brincar com as crianças, $84 \%$ que conversam com as crianças a respeito de coisas de interesse delas e 93\% costumam fazer carinho na criança.

Muniz e colaboradoras ${ }^{9}$, em estudo internacional, de abordagem quantitativa, também focalizaram as atividades de rotina desempenhadas pelas crianças em idade pré-escolar no contexto familiar e encontraram relações significativas, de forma que quanto mais atividades as crianças compartilhavam com seus pais e quanto mais frequentes elas fossem, maiores eram os níveis de saúde mental $^{9}$.

Assim, embora no presente estudo estas variáveis não tenham sido relacionadas de forma estatisticamente significativa com a saúde mental das crianças, elas indicam que os responsáveis pelas crianças participantes do estudo parecem interagir com as mesmas no cotidiano. Considerando que apenas os responsáveis foram ouvidos no presente estudo e que as questões foram apresentadas a partir de um questionário objetivo, indica-se a necessidade de mais investigações que se debrucem sobre as dinâmicas das relações cotidianas familiares, a partir de métodos de pesquisa variadas e que considerem a ótica dos diferentes membros familiares envolvidos no cuidado da criança e, também, das próprias crianças.

Dando continuidade a discussão e agregando mais elementos para aprofundá-la, neste estudo foi possível verificar que a existência de brigas na família foi uma variável identificada como um fator de risco para a saúde mental das crianças. Os dados descritivos apontaram que $31 \%$ das famílias das crianças participantes vivenciam essa realidade em seu cotidiano, sendo que em $90 \%$ dessas famílias o principal tipo de briga vivenciado é a discussão.

Segundo os resultados da presente investigação, quando os responsáveis relataram a existência de brigas na família, as crianças apresentaram mais problemas relativos à saúde mental e se comportaram menos de forma pró-social, o que é reforçado pelo escore geral do SDQ que também foi mais alto nessas condições.

O presente estudo apresenta uma limitação importante referente aos achados sobre a existência de brigas na família, que é o fato de não ter utilizado instrumento padronizado de análise de existência de violência intrafamiliar, o que provavelmente possibilitaria resultados mais consistentes e fidedignos sobre essa problemática. Portanto, a discussão desse resultado fica limitada, considerando que a existência de brigas se configura como uma informação inicial sobre os aspectos de risco que envolvem o ambiente familiar, pois é uma variável que nem sempre é negativa e pode ser considerada como "esperada" em todas as famílias, cujas relações muitas vezes envolvem 
conflitos e discussões que buscam a resolução de problemas cotidianos.

De qualquer forma, os achados vão ao encontro do que tem sido apontado por estudos que relacionaram problemas relativos à saúde mental infantil e vivência de violência intrafamiliar. Tais estudos indicam que a violência intrafamiliar está bastante correlacionada ao desenvolvimento de problemas socioemocionais em crianças $^{4,16}$.

No que se refere à Dimensão "Criança" do QAC, foi possível observar que o desempenho escolar das crianças na visão do responsável, bem como a repetência escolar vivenciada se relacionaram com a saúde mental das mesmas, isto é, quanto pior foi o desempenho da criança na escola, na avaliação dos responsáveis, mais ela apresentou problemas emocionais, problemas de conduta, hiperatividade e menos ela se comportou de forma prósocial, ou seja, mais problemas referentes à saúde mental ela apresentou.

Este resultado sugere que a saúde mental da criança influencia e é influenciada pelo desempenho escolar, podendo melhorar ou atrapalhar esse aspecto da vida da criança. Alguns estudos têm se dedicado a investigar de forma mais aprofundada essa relação ${ }^{17,18}$.

Burt et al..$^{18}$ desenvolveram um estudo longitudinal no qual acompanharam uma amostra de 205 crianças em três momentos de suas vidas: na idade escolar, dez anos e vinte anos depois, a fim de investigar efeitos cascata relativos à continuidade de problemas socioemocionais na infância, adolescência e início da idade adulta, bem como as relações entre esses problemas e o desempenho escolar. Os resultados encontrados indicaram o seguinte efeito cascata: problemas externalizantes identificados na idade escolar (até 12 anos) prejudicam o desempenho escolar na adolescência que, por sua vez, está associado a problemas internalizantes no início da vida adulta.

Além disso, o estudo também encontrou relações entre problemas de comportamento e desempenho escolar nas fases estudadas ${ }^{17}$.

Como um ciclo, acredita-se que o mau desempenho escolar também pode exercer um papel de risco, influenciando nas relações parentais, no desenvolvimento do senso de autoeficácia, podendo empobrecer o autoconceito e a autoestima das crianças, prejudicando ainda mais seu desenvolvimento socioemocional ${ }^{19}$.

Os dados e discussões emergidas a partir do presente estudo revelam a necessidade de mais investigações que busquem aprofundar na dinâmica cotidiana de atividades e relações de famílias com crianças, buscando melhor compreender os significados do fazer cotidiano nas singularidades de cada família e o impacto destes no processo de desenvolvimento socioemocional das crianças, buscando, assim, um entendimento mais amplo e complexo a respeito das formas de organização e relacionamento familiar e subsidiando ações mais efetivas advindas de equipamentos e de profissionais de saúde, educação e assistência social que acompanham crianças que vivenciam problemáticas diversas, principalmente aquelas que apresentam sofrimento psíquico.

Aponta-se também que colocar foco sobre o cotidiano e sobre as práticas e engajamento em atividades nos diversos contextos do desenvolvimento têm sido alvo de estudos contemporâneos ${ }^{20,21}$. Tal tendência parece reforçar a compreensão sobre a importância do dia-a-dia nos níveis de saúde, qualidade de vida e engajamento social, questões estas focalizadas pelos profissionais terapeutas ocupacionais em suas práticas e sobre as quais podem produzir potentes e relevantes conhecimentos.

Agradecimento: à Profa. Dra. Thelma Simões Matsukura que orientou este trabalho e contribuiu sobremaneira para o seu desenvolvimento.

\section{REFERÊNCIAS}

1. Cid MFB, Matsukura TS. Problemas de saúde mental em escolares e seus responsáveis: um estudo de prevalência. Rev Ter Ocup Univ São Paulo. 2014;25(10):1-10. http://dx.doi. org/10.11606/issn.2238-6149.v25i1p1-10.

2. Fernandes ASA, Matsukura TS, CID MFB. Saúde mental infantil em contextos de desvantagem socioeconômica: fatores de risco e proteção. Cad Ter Ocup UFSCar, São Carlos. 2014;22(2):251-62. http://dx.doi. org/10.4322\%2Fcto.2014.047.

3. Ferrioli, SHT, Marturano EM, Puntel LP. Contexto familiar e problemas de saúde mental infantil no Programa Saúde da Família. Rev Saúde Pública. 2007;41(2):251-59. http://dx.doi. 
org/10.1590/S0034-89102006005000017.

4. Sá DGF, Bordin IAS, Martin D, Paula CSP. Fatores de risco para problemas de saúde mental na infância/adolescência. Psicologia Teor Pesq. 2010. 26(4) 643-652. http://dx.doi. org/10.1590/S0102-37722010000400008

5. Souza MTS, Oliveira AL. Fatores de proteção familiares, situações de risco, comportamentos e expectativas de jovens de baixa renda. In: Dell 'Aglio DD, Koller SH, organizadores. Adolescência e juventude: vulnerabilidade e contextos de risco e proteção. São Paulo: Casa do Psicólogo; 2011.

6. Gomide PIC. Inventário de estilos parentais (IEP): modelo teórico - manual de aplicação, apuração e interpretação. Petrópolis: Vozes; 2006.

7. Cecconello AM, Koller SH. Competência social e empatia: um estudo sobre resiliência com crianças em situação de pobreza. Est Psicol (Natal). 2003;5(1):71-93. http://dx.doi. org/10.1590/S1413-294X2000000100005.

8. Cid MFB. Saúde mental de escolares: um estudo de prevalência e de fatores de risco e proteção [tese]. São Carlos: Centro de Educação e Ciências Humanas, Universidade Federal de São Carlos; 2011.

9. Muñiz EI, Silver EJ.; STEIN REK. Family routines and social-emotional school readiness among preschool age children. J Dev Behav Pediatr. 2014;35(2):93-9. doi: 10.1097/ DBP.0000000000000021.

10. Heller A. O cotidiano e a história. São Paulo: Paz e Terra; 2000.

11. Galheigo SM. O cotidiano na terapia ocupacional: cultura, subjetividade e contexto histórico-social. Rev Ter Ocup Univ São Paulo. 2003;14(3):104-9. http://dx.doi.org/10.11606/ issn.2238-6149.v14i3p104-109.

12. Goodman R. Psychometric properties of the Strengths and Difficulties Questionnaire (SDQ). J Am Acad Child Adolesc Psychiatr. 2001;40(11):1337-45. doi: http://dx.doi. org/10.1097/00004583-200111000-00015.

13. Cury CR, Golfeto, JH. Strengths and difficulties questionnaire
(SDQ): a study of school children in Ribeirão Preto. Rev Bras Psiquiatr. 2003;25(3):139-45. http://dx.doi.org/10.1590/ S1516-44462003000300005

14. Manzini EJ. Considerações sobre a elaboração de roteiro para entrevista semi- estruturada. In: Marquezine MC, Almeida MA, Omote S, organizadores. Colóquios sobre Pesquisa em Educação Especial. Londrina: Ed. UEL; 2003. p.11-25.

15. Dishion TJ., McMahon RJ. Parental monitoring and the prevention of child and adolescent problem behavior: a conceptual and empirical formulation. Clinl Child Fam Psychol Rev. 1998;1(1):61-75. doi: 10.1023/A:1021800432380.

16. Maldonado DPA, Williams LCA. O comportamento agressivo de crianças do sexo masculino na escola e sua relação com a violência doméstica. Psicol Est, Maringá. 2005;10(3):353-62. http://dx.doi.org/10.1590/S1413-73722005000300003.

17. Burt KB, Obradović J, Long JD, Masten AS. The interplay of social competence and psychopathology over 20 years: testing transactional and cascade models. Child Dev. 2008;79(2):35974. doi: 10.1111/j.1467-8624.2007.01130.x.

18. D'Avila-Bacarji KMG, Marturano EM, Elias LCS. Suporte parental: um estudo sobre crianças com queixas escolares. Psicol Est, Maringá. 2005;10(1):107-15. http://dx.doi. org/10.1590/S1413-73722005000100013.

19. Marturano EM, Linhares, MB, Loureiro SR, organizadores. Vulnerabilidade e proteção: indicadores na trajetória de desenvolvimento do escolar. São Paulo: Casa do Psicólogo/ FAPESP; 2004.

20. Salles MM, Matsukura TS. Estudo de revisão sistemática sobre o uso do conceito de cotidiano no campo da terapia ocupacional no Brasil. Cad Ter Ocup UFSCar. 2013;21(2):26573. doi: http://dx.doi.org/10.4322\%2Fcto.2013.028.21. Ferreira MCT, Marturano EM. Ambiente familiar e os problemas de comportamento apresentados por crianças com baixo desempenho escolar. Psicol Reflex Crít. 2002;15:3544. Disponível em: http://www.scielo.br/pdf/prc/v15n1/ a05v15n1.pdf. 